\title{
Seismic and Wind High-Rise Building Design
}

\author{
Mazhiev Kh. N. \\ The Faculty of Construction \\ Grozny State Oil Technical University named after M. D. \\ Millionshchikov \\ The Department of Materials Science \\ Complex Research Institute. Kh. I. Ibragimov of the \\ Russian Academy of Sciences \\ The Department of Technical Sciences \\ The Academy of Sciences of the Chechen Republic \\ Grozny, Russia \\ seismofund@mail.ru

\section{Mazhiev K. Kh.} \\ The Faculty of Construction \\ Grozny State Oil Technical University named after M. D. \\ Millionshchikov \\ The Department of Materials Science \\ Complex Research Institute. Kh. I. Ibragimov of the \\ Russian Academy of Sciences \\ The Faculty of Public Administration \\ Chechen State University \\ Grozny, Russia \\ m.k.kh@mail.ru \\ Radnaev O. B. \\ Federal State Unitary Enterprise for Design, Construction \\ and Reconstruction of Infrastructure Projects» \\ Moscow, Russia \\ o.radnaev@psrrf.ru \\ Mazhiev Adam Kh. \\ The Department of Materials Science \\ Complex Research Institute. Kh. I. Ibragimov of the \\ Russian Academy of Sciences \\ The Department of Technical Sciences \\ The Academy of Sciences of the Chechen Republic \\ Grozny, Russia \\ adammazhiev@mail.ru
}

\author{
Zaalishvili V. B. \\ The Faculty of Construction \\ Grozny State Oil Technical University named after M. D. \\ Millionshchikov \\ Complex Research Institute. Kh. I. Ibragimov of the \\ Russian Academy of Sciences
}

The Geophysical Institute of Vladikavkaz Scientific Center of the Russian Academy of Sciences

Vladikavkaz, Russia

vzaal@mail.ru

Panasyuk L. N.

The Faculty of Industrial and Civil Engineering

Don State Technical University

Rostov-on-Don, Russia

panasjuk.leonid@gmail.com

\author{
Mazhieva A. Kh. \\ The Faculty of Construction \\ Grozny State Oil Technical University named after M. D. \\ Millionshchikov \\ Grozny, Russia \\ a.mazhieva@mail.ru
}

\section{Mazhiev Aslan Kh.}

The Department of Materials Science

Complex Research Institute. Kh. I. Ibragimov of the

Russian Academy of Sciences

The Department of Technical Sciences

The Academy of Sciences of the Chechen Republic

The Faculty of Public Administration

Chechen State University

Grozny, Russia

aslanmazhiev@mail.ru

\footnotetext{
Abstract-The article presents the results of wind modeling with the effects on high-rise building in the aerodynamic tunnel; the data were applied to complete the calculations of the loadbearing structures with wind and seismic loads. This resulted in obtaining the forms of natural oscillations of a high-rise building, the maximum displacement and acceleration of the top of the building, the internal forces in the supporting structures of the
}

aboveground part, in the base plate and in the piles, and the parameters of their reinforcement.

Keywords-Building, construction, impact, load, calculation, displacement, internal forces, testing 


\section{INTRODUCTION}

The building in question is quite unique, with the complex space-planning and design solutions that do not have any analogues. In Construction Rules (CR)20.13330.2016 "oads and Impacts. Updated Construction Rules and Regulations" 2.01.07-85*", as well as in other national and foreign works [2, $5,6,9,10,12,13,15,16]$ there is no information on the distribution of wind load on the enclosing structures for the constructions of this type. Usually, in such cases, these loads are determined on the basis of model aerodynamic test data. Moreover, the results of testing of structures of this type show that in addition to their geometric shape, other factors that are not usually taken into account in the design practice can influence the magnitude and distribution of the calculated wind loads. It should be noted that on the studied area there are other buildings and structures that affect the change in the structure of the wind flow and, as a result, form the existing wind loads.

The problems in discussion can be solved only by using the results of model tests of structures in the aerodynamic tunnel. The experimental study of the distribution of wind loads on the enclosing surfaces of the building model was carried out in a specialized aerodynamic or wind tunnel located in the research, design and construction company UNIKON.

\section{MethodS AND MATERIALS}

Aerodynamic tests of the high-rise building model were carried out in the wind tunnel of UNIKON design and construction company [17]. The purpose of these tests was to determine the design wind loads affecting on the bearing and enclosing structures of the building and to identify their peak values, as well as the flow rate in pedestrian zones. The choice of this testing aerodynamic installation at UNIKON primarily resulted from the fact that due to its design features it allows us to simulate real wind conditions and thus to the greatest extent to meet the requirements for such experimental work. In particular, the published data indicate that the values and distribution of aerodynamic parameters on the surface of the investigated structure significantly depend on the nature and structure of the artificial flow and its compliance with natural wind flows.

The wind tunnel 3-AT-17.5 / 3 of UNICON is located in the horizontal plane (Fig. 1) and has a long working part and a reverse channel.

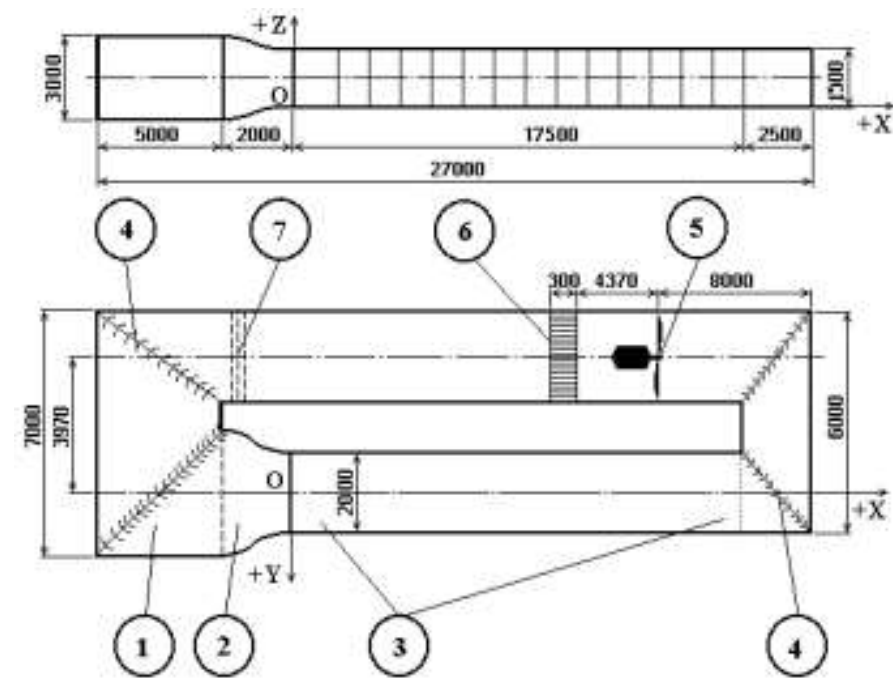

Fig. 1. Scheme of wind tunnel 3-AT-17.5 / 3 of UNICON

The outlet section of the nozzle has a rectangular shape with a width of $2.0 \mathrm{~m}$ and a height of $1.5 \mathrm{~m}$. The length of the working part is $17.5 \mathrm{~m}$.

As this aerodynamic installation has the elongated working part, it makes it possible to simulate the structure and other features of wind conditions including the following: the change in the settled wind speed in height, the structure and scale of the turbulence of the dynamic component of the wind flow. The flow in pipes with the elongated working part results from the same effects as the wind in natural conditions, i.e. due to the interaction with the underlying surface of the wind tunnel and during the flow around the obstacles placed in it. Changing the roughness (Fig. 2) on the lower surface of the pipe, it is possible to create gradient flows, taking into account the peculiarities of the localities according to the classification of CR (type A, B and $\mathrm{C}$ ).

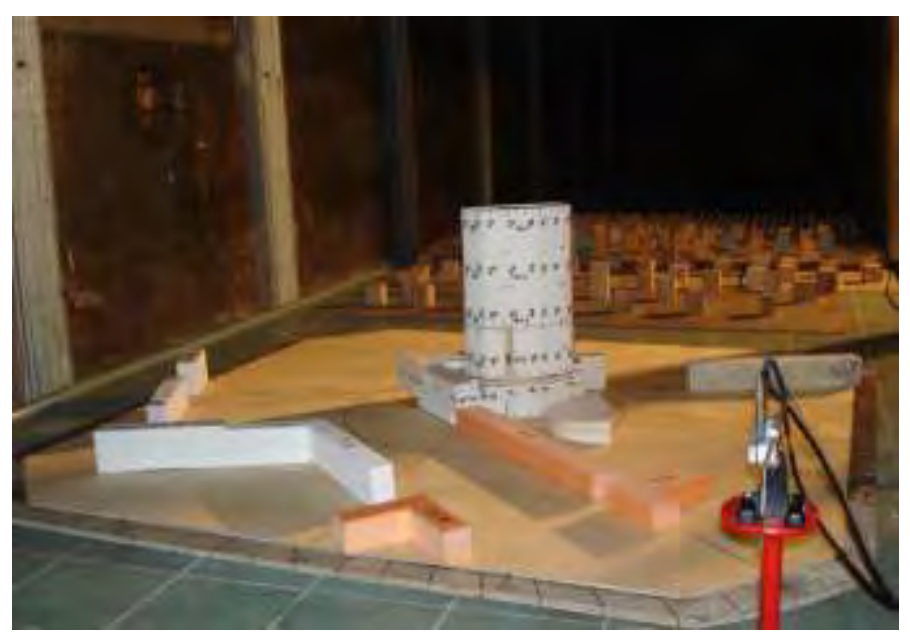

Fig. 2. The general view of the elements of roughness and model structures in the wind tunnel 3-AT-17.5 / 3 of UNICON

Fig. 3 and 4 show the change in the average flow rate depending on the distance $\mathrm{z}$ from the lower wall of the wind tunnel, as well as the energy spectrum of the flow. These data 
are recorded in the Unicon wind tunnel at the installation site of the model (at a distance of $\sim 10 \mathrm{~m}$ from the pipe nozzle).

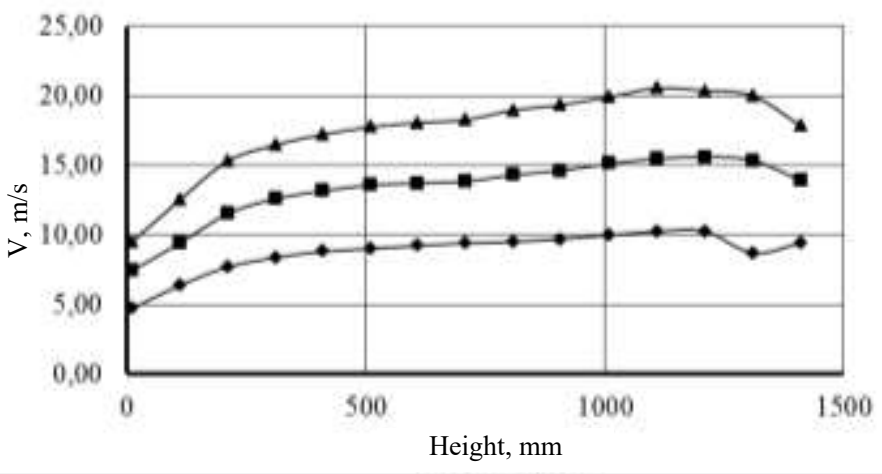

Fig. 3. Changing the average flow rate in the wind tunnel 3-AT-17.5/3 of UNICON

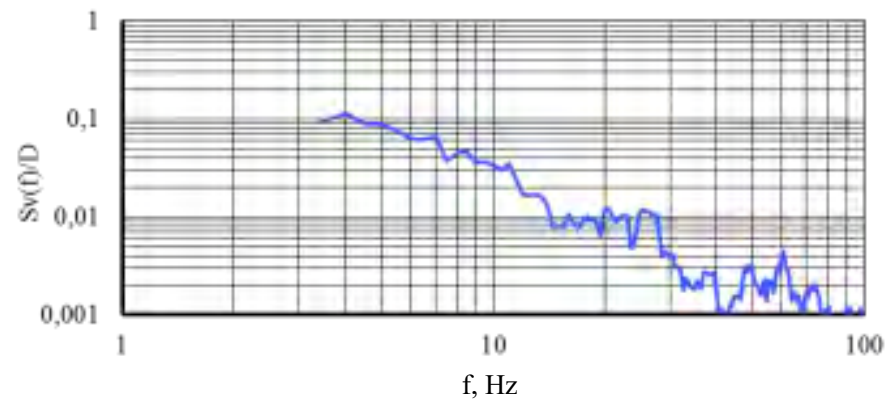

Fig. 4. Energy spectrum of flow in the wind tunnel 3-AT-17.5 / 3 of UNICON

During the model tests of the building under consideration, we selected the location and dimensions of the roughness elements in order to sustain the correspondence of the flow structure, taking into account the scale of the simulation, to the terrain of type B.

During the experimental studies, neighbouring buildings and structures located in the immediate vicinity of the building were also modeled.

To perform the whole complex of works, models of all structures were made in the scale of 1:300 (Fig. 2) with their geometric similarity.

The demountable models of buildings on a scale of 1: 300 were made of sheeted polystyrene, polyvinyl chloride and wood, and are equipped with sensors that measure the pulsation and average pressure components.

During the tests, the relative cross-section area reduction ratio $\varphi$ of the working pipe did not exceed 8\%, which corresponds to the requirements for experimental studies of this kind.

The test procedure included the measurements for each building:

- the average component of the pressure;

- pulsation component of the pressure;

- wind speeds in pedestrian areas.
When conducting experimental studies, the angle of the leakage flow was changed with the intervals $\Delta \alpha=10^{\circ}$.

The average pressure component was measured at 128 points of 6 horizontal sections:

$$
z / h=0.12,0.28,0.50,0.71,0.93,
$$

where:

$z$ is the distance from the floor of the wind tunnel;

$h$ is the height of the building model.

For each realization of pressure pulsations $p(t)$ we recorded for a period of time $T=15 C$ with the intervals $\Delta t=$ $0.002 c$. The recorded values of $p_{i}(i=1, \ldots, 10000)$ were then smoothed at an interval of $\Delta t=0.01 \mathrm{sec}$. The thus obtained values of pressure

$$
\widetilde{p}_{i}=\frac{1}{10} \sum_{j=1}^{10} p_{10(i-1)+j} \quad i=1, \ldots 1000
$$

taking into account the scale factors correspond to 1-3 seconds wind pressure for the real construction.

In the course of special model tests in the wind tunnel UNIKON, the research team obtained the data on the distribution of aerodynamic coefficients and pulsations of wind load on the surface of the enclosing structures of the studied building. These results made it possible to determine the peak (maximum and minimum) values of the wind load and the corresponding aerodynamic coefficients. As an example, Fig. 4-7 show the calculated values of the average component of the wind load for the two variants of the most unfavorable loading at angles of attack $\alpha=160^{\circ}$ and $300^{\circ}$, at the level of $1-8$ and 27 and the higher floors

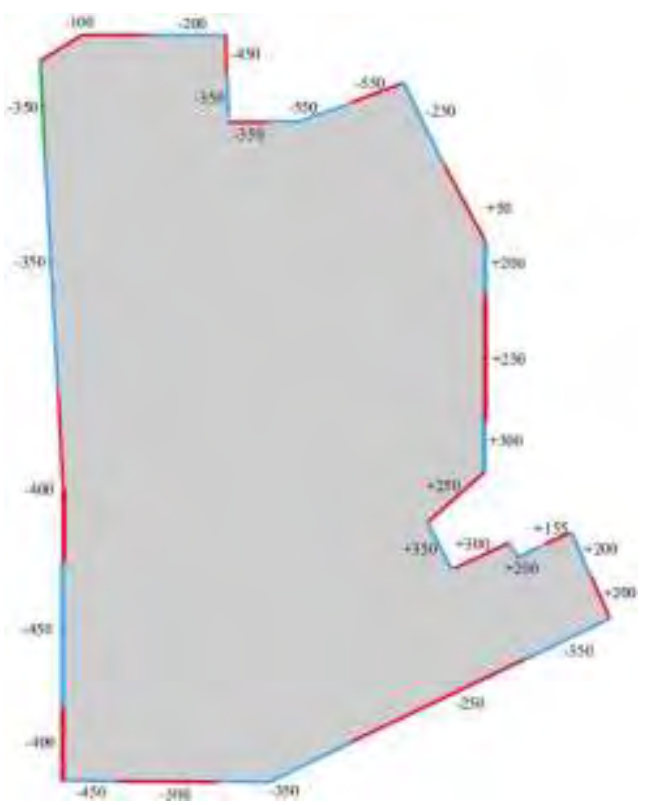

Fig. 4. The calculated values of the average component of the wind load (PA). Variant 1. Floors 1-8. 


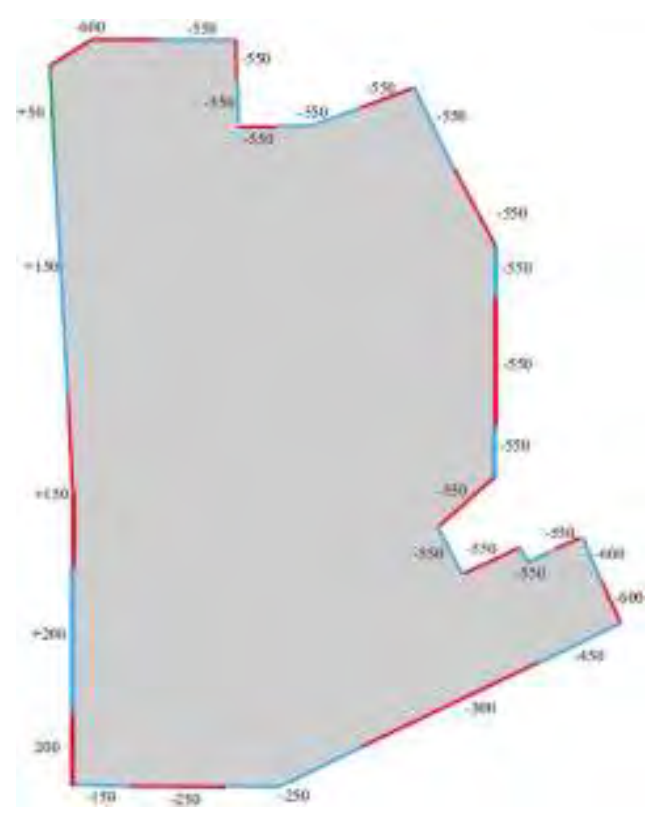

Fig. 5. The calculated values of the average component of the wind load (PA). Variant 2. Floors 1-8.

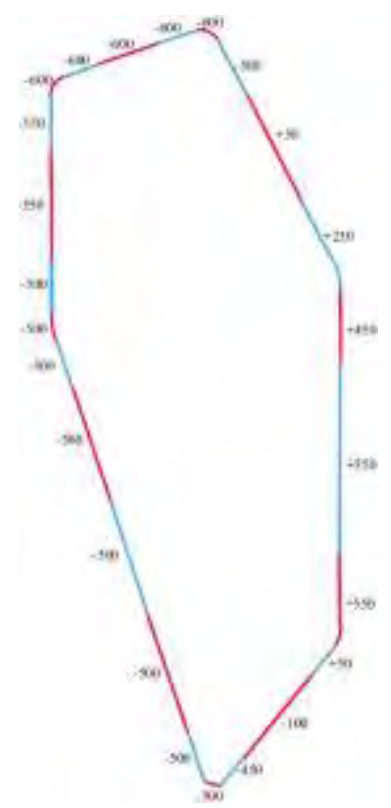

Fig.4. The calculated values of the average component of the wind load (PA). Variant 1. Floors 27 and higher

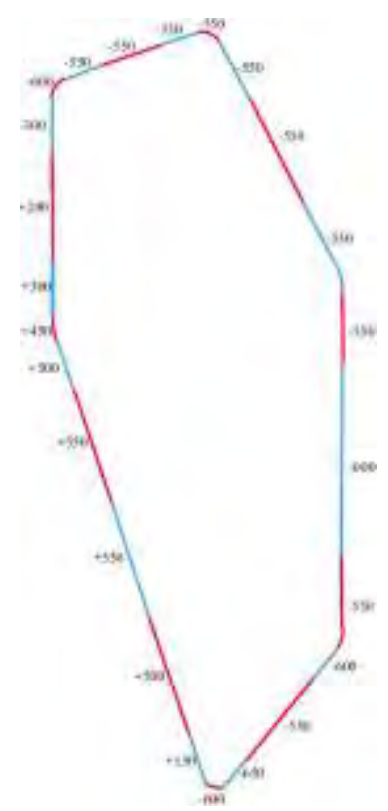

Fig. 7. The calculated values of the average component of the wind load (PA). Variant 2. Floors 27 and higher

Basic provisions for the calculation of load-bearing structures of a high-rise building.

\section{Building criticality rating}

The calculation of the building criticality rating of the highrise part of the complex - I.THE height of the building-more than $100 \mathrm{~m}$.

The increased level of criticality is accepted as for the building, the failures of which can lead to serious economic and social consequences [1].

Evaluation of the durability of the building. The working life of the main structures of the building is at least 100 years.

Structural rigidity of the building.

It is assumed that the horizontal rigidity of the building in all directions will provide stability and perception of seismic and wind loads [3, 4, 8, 14].

Vertical load-bearing structures. The main load-bearing structures are to be made of the reinforced concrete, with flexible reinforcement. Bearing walls and columns are to be made of concrete class B30.

THE type of reinforcement is class A400 (The National Standard GOST 5781-82) is considered to provide the required fire resistance and fire safety of the bearing structures of the building.

The thickness of the walls and columns varies depending on the height of the building.

Reinforcement ratios:

- in columns with flexible fittings - not less than $1 \%$ and not more than $7 \%$;

- in walls and cores of rigidity - not less than $0,5 \%$. 
Foundation. In order to prevent the tilts of the high-rise building the pile type of the base (from bored piles) is to be performed. For the foundation forms the concrete of class B30, the thickness of the foundation plate $-1800 \mathrm{~mm}$. The ratio of reinforcement is not less than $0.15 \%$.

Intermediate slabs. Load-bearing structures of the intermediate slabs are made of reinforced concrete class B30.

A constructive solution of these slabs results from the calculation based on the necessity to limit their fire resistance. The protective layer of reinforcement consideres the requirements of fire safety.

The calculation of the load-bearing structures of the intermediate slabs are alsoin accordance with the forces caused by different vertical deformations in the columns and walls.

The coefficient of reinforcement in the slabs is not less than $0.25 \%$.

Horizontal movement of the top of a high-rise building. The maximum allowable roll of the calculated building is determined by moving the top of the building horizontally by 1/500 of the total height. The calculated roll parameter is determined according to the eccentricity of the vertical load and the possible wind impact.

Horizontal movements are determined according to the roll (rotation) of the foundations. The foundation roll is determined according to the horizontal wind load, taken into account in the amount of $50 \%$ of the normative value.

The lack of parallelism of the story cells should not exceed $1 / 700$ scale.

Vertical limit deflections of structural elements. The maximum deflections of ceilings from permanent and temporary long-term loads, with a span of $6 \mathrm{~m}$ (aesthetic and psychological requirements)-L/200.

The limit deflections of slabs from the concentrated load of $1 \mathrm{kN}$ in the middle of the span (physiological requirements) $0.7 \mathrm{~mm}$.

The load on the building. The calculation is performed according to BR 20.13330.2016 for the following types of loads:

- vertical;

- horizontal from the wind;

- snow load.

Wind loads on the building.

Wind district-I

Type of terrain-B

Standard value of wind pressure

$\mathrm{w}_{0}=0.23 \mathrm{kPa}$.

The reliability coefficient for wind load (for buildings higher than $100 \mathrm{~m}$ )

$\gamma_{\mathrm{f}}=1.5$

The normative value of the average component of the wind load is determined in accordance with [1].
Wind load is defined as the sum of average and pulsation components.

The forces and displacements of the structure are determined separately from the average component and from the pulsation component corresponding to each form of oscillations.

The total forces and displacements from the wind load are defined as the sum of the average component and the root of the sum of the squares of the values of the corresponding forces and displacements of the pulsation components for all considered forms of oscillations. In this case, the sign of the obtained value from the pulsation component is taken to be equal to the sign of the average component.

The value of the pulsation component of the wind load is determined for each form of vibration in the form of a system of inertial forces applied to the interstory slabs of the structure.

Logarithmic decrement of oscillations for reinforced concrete building

$$
\delta=0.3
$$

The limit value of the natural frequency at which it is allowed not to take into account the inertia forces arising from the oscillations of the corresponding eigenform $f_{l}=0.95 \mathrm{~Hz}$.

Due to the complex aerodynamics of a high-rise building, aerodynamic coefficients originated from the results of blowing the model of a high-rise building and the neighbourhood around the building in the wind tunnel.

The weight loads Adopted in accordance with BR 20.13330.2016 "Loads and impacts".

\section{1) the floors/ceilings of the building \\ a) self-weight of the monolithic slab (constant load)}

The estimated thickness

$$
\mathrm{t}=220 \mathrm{MM}
$$

The reliability coefficient for the pressure of the concrete when calculating the resistibility

$$
\gamma_{\mathrm{f}}=1.1
$$

Total: the calculated weight of the slab (resistibility calculation) - $0.605 \mathrm{TF} / \mathrm{m}^{2}$

\section{b) short-term load in the office premises}

The full value of the standard load in the office space

$$
\mathrm{p}=0.20 \mathrm{TF} / \mathrm{m}^{2}
$$

The reliability coefficient of the load for a uniformly distributed load is less than 0.2 TFestimated short-term load on the floor/ceiling $-0.240 \mathrm{TF} / \mathrm{m} 2 / \mathrm{m}^{2}$

$$
\gamma_{\mathrm{f}}=1.2
$$

Total: $\rho=1.8 \mathrm{t} / \mathrm{m} 3$, thickness-50 mm, $\gamma \mathrm{f}=1.3$, calculated load- $0.12 \mathrm{TF} / \mathrm{m} 2$ estimated short-term load on the floor/ceiling $-0.240 \mathrm{TF} / \mathrm{m}^{2}$ 


\section{d) floor construction}

Cement-sand screed

$\rho=1.8 \mathrm{t} / \mathrm{m}^{3}$, thickness-50 mm, $\gamma_{\mathrm{f}}=1.3$, calculated load$0.12 \mathrm{TS} / \mathrm{m}^{2}$

The separate floor thickness is $50 \mathrm{~mm}$, the calculated load $0.070 \mathrm{TF} / \mathrm{m}^{2}$

Total: the calculated load of the floor structure $-0.19 \mathrm{TF} / \mathrm{m}^{2}$

e) weight of enclosing walls and partitions

the calculated load of the intermediate slab $-0.265 \mathrm{TF} / \mathrm{m}^{2}$

TOTAL: The calculated total load of the intermediate slabs $-1.3 \mathrm{TF} / \mathrm{m}^{2}$

\section{2) Internal load-bearing walls of the building}

When defining loads design door heights is $210 \mathrm{~cm}$

a) own weight of monolithic walls

Calculated from the volume of walls based on the density of reinforced concrete

$$
\rho=2.5 \mathrm{~T} / \mathrm{m}^{3}
$$

The reliability coefficient for the pressure of the concrete when calculating the resistibility

$\gamma_{\mathrm{f}}=1.1$

\section{b) two layers of plaster $1 \mathrm{~cm}$ thick on each side of the wall}

$\rho=1.8 \mathrm{t} / \mathrm{m}^{3}$, thickness- $20 \mathrm{~mm}, \gamma_{\mathrm{f}}=1.3$, calculated load$0.05 \mathrm{TF} / \mathrm{m}^{2}$

\section{3) Outside glazing \\ calculated load $-0.05 \mathrm{TF} / \mathrm{m}^{2}$ \\ 4) Snow load}

Calculated snow load on the surface- $0.2 \mathrm{TF} / \mathrm{m}^{2}$.

\section{5) Other loads}

The weight of the stairs $-0.700 \mathrm{TF} / \mathrm{m}^{2}$

Temporary load on the stairs- $0.3 * 1.2=0.36 \mathrm{TF} / \mathrm{m}^{2}$

Temporary load in the corridors- $0.3 * 1.2=0.36 \mathrm{TF} / \mathrm{m}^{2}$.

The loads on technical floors, rooms for warehouses of materials, parking lots, as well as loads from engineering equipment are taken in the form of evenly distributed temporary loads:
a) for technical floors $-1.0 \mathrm{TF} / \mathrm{m}^{2}$;
b) for parking lots- $0.5 \mathrm{TF} / \mathrm{m}^{2}$;
C) for warehouses- $0.5 \mathrm{TF} / \mathrm{m}^{2}$;
d) for cornices $-0.14 \mathrm{TF} / \mathrm{m}^{2}$

\section{Load combinations.}

The first basic combination:
All weight loads (constant, temporary, short-term) are with the coefficient $\psi 1=\psi 2=1$. Wind loads are not taken into account.

In calculation of the main load combination in high-rise buildings there is one permanent and one temporary load (short-term with the full normative value), excluding the reduction factors according to BR 20.13330.2016 "Loads and impacts".

\section{The second basic combination:}

All constant weight loads are taken with the coefficient $\psi_{1}$ $=1$. Wind loads and short-term loads on the floor are calculated with the coefficient $\psi_{2}=0.9$.

The coefficients of operating conditions of the building structure.

\section{The concrete of the building walls}

$\gamma_{\mathrm{b} 2}=0.9$-the operating conditions of the structures are not favourable for increasing the strength of concrete

$\gamma_{\mathrm{b} 3}=0.9$-concreting in vertical position

Total: $\gamma \mathrm{b}=0.81$

\section{Building floor concrete}

$\gamma_{\mathrm{b} 2}=0.9$-the operating conditions of the structures are not favourable for increasing the strength of concrete

Total: $\gamma b=0.9$

\section{The concrete foundation slab of the building}

$\gamma_{\mathrm{b} 2}=0.9$-the operating conditions of the structures are not favourable for increasing the strength of concrete

Total: $\gamma_{b}=0.9$

\section{Rod fittings A400}

$\mathrm{y}_{\mathrm{s}}=1.0$ - for longitudinal reinforcement

$\mathrm{y}_{\mathrm{s} 1}=0.8$ - the design of the unevenness of the stress distribution along the length in the transverse reinforcement

\section{Requirements for crack resistance.}

The foundation plate of the building

The limitation by the width is not prolonged $\mathrm{a}_{\text {сгс } 1}=0.4 \mathrm{~mm}$ and long $\mathrm{a}_{\mathrm{crc} 2}=0.3 \mathrm{~mm}$ crack opening (category 3 , in the soil at the steady state level of groundwater).

\section{The floors/ceilings of the building}

The limitation by the width is not prolonged $\mathrm{a}_{\mathrm{crcl}}=0.4 \mathrm{~mm}$ and long $\mathrm{a}_{\mathrm{crc} 2}=0.3 \mathrm{~mm}$ crack opening (category 3 , indoors).

Taking into account the accepted values of loads and coefficients, the calculations were carried out estimating the wind and seismic effects with the assistance of the software complex "Lira" [7, 11]. Fig. 8-12 show the first five forms of vibrations of a high-rise building, obtained from the calculation of the dynamic effect of the wind. Fig. 13 shows the isofields 
movements in the wind in the direction of the Y-axis. The maximum movement of the top of the building was 199,439 $\mathrm{mm}$.

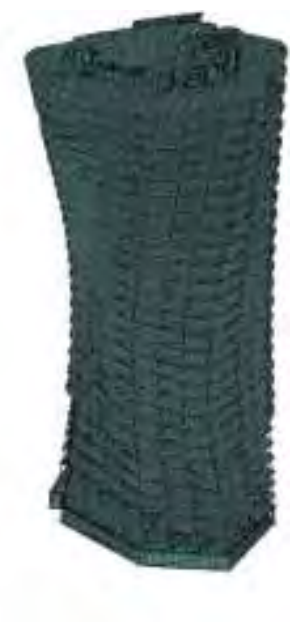

Fig. 8. The shape of the building's own oscillations. Form-1, frequency- $0.15 \mathrm{~Hz}$

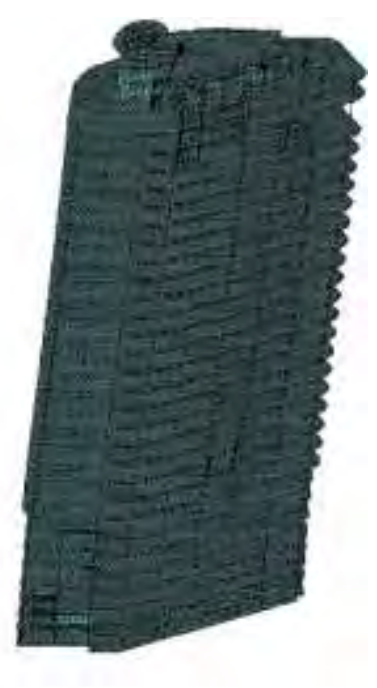

Fig. 9. The shape of the building's own oscillations. Form-2, frequency-0.181 $\mathrm{Hz}$

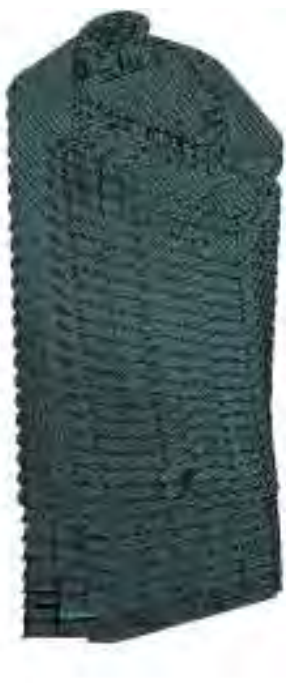

Fig. 10. The shape of the building's own oscillations. Form-3, frequency-0.282 $\mathrm{Hz}$

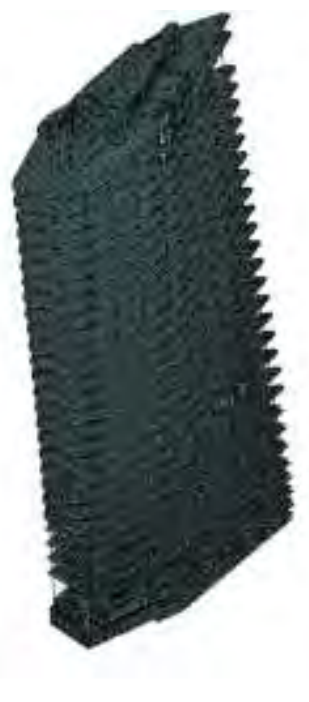

Fig.11. The shape of the building's own oscillations. Form-4, frequency-0.575 $\mathrm{Hz}$ 


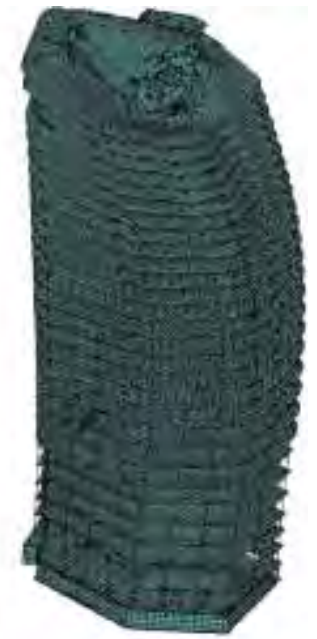

Fig. 12. The shape of the building's own oscillations. Form-5, frequency- 0.826 $\mathrm{Hz}$

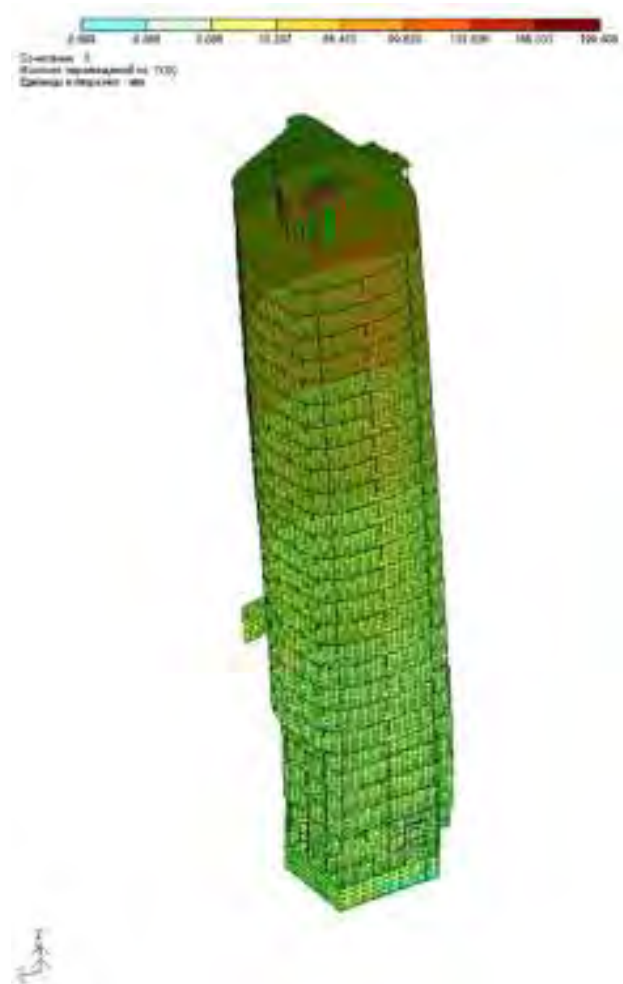

Fig. 13. Insulation of the premises. Wind in the direction of Y-axis. The maximum movement of the top of the building was $199,439 \mathrm{~mm}$.

Analysis of the obtained insulations shows that the dynamic displacement of the top of the building under seismic effects with intensity of 6 points is up to $187 \mathrm{~mm}$ (Fig. 14), and at seismic influence of greater intensity, the values of displacements would make for 7 points - $406 \mathrm{~mm}$ (Fig. 15), 8 points $-846 \mathrm{~mm}, 9$ points $-1730 \mathrm{~mm}$.

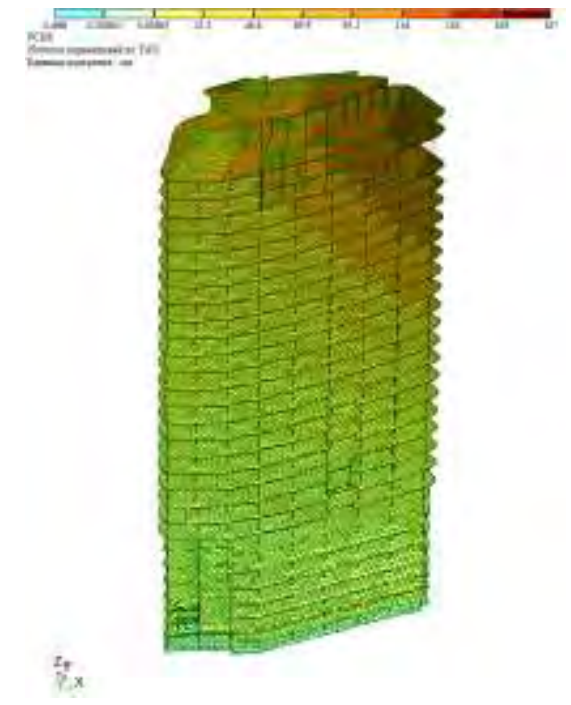

Fig. 14. Insulation of the premises. Seismic effects in the direction of Y-axis (6 points). The maximum movement of the top of the building-187 $\mathrm{mm}$

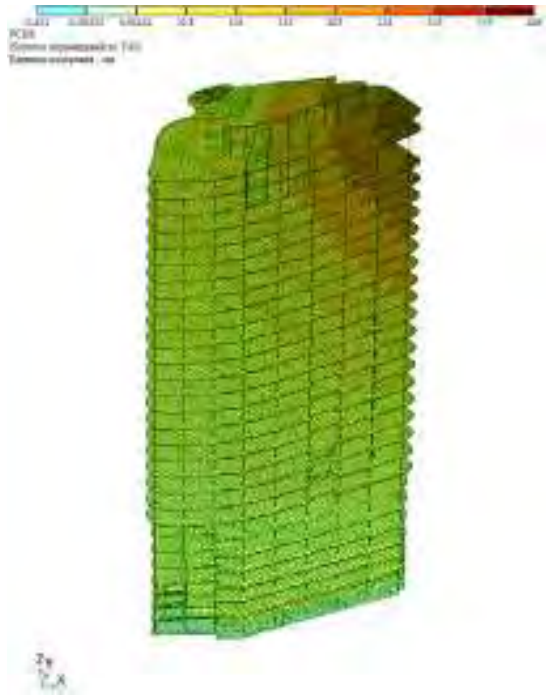

Fig. 15. Insulation of the premises. Seismic effects in the direction of Y-axis (7 points). The maximum movement of the top of the building-406 $\mathrm{mm}$

\section{RESULTS}

The results of simulation of wind impacts on a high-rise building in the wind tunnel provide the data for the calculation of load-bearing structures of a high-rise building on wind impacts is performed. This resulted in obtaining the forms of natural oscillations of a high-rise building, the maximum displacement and acceleration of the top of the building, the internal forces in the supporting structures of the aboveground part, in the base plate and in the piles, and the parameters of their reinforcement. At the same time, the verification of calculations for seismic effects of different intensity were performed.

\section{CONCLUSION}

The calculations of the high-rise building on wind and seismic effects confirm the rationality of the design decisions. The building spatial rigidity is ensured by the combined efforts 
of the columns, core rigidity, rigidly connected to the baseplate and horizontal hard disks of the inremediate slabs. Structural solutions of butt joints, support elements and assemblies ensure the transfer of forces and joint work of load-bearing structures. It should be noted that the maximum movement of the top of the building from the wind exceeds the maximum movement of the top of the building from seismic forces of 6 points. At a higher intensity of seismic effects, the maximum movement of the top of the building dominates the movement from the wind.

\section{References}

[1] BR 20.13330.2016 " Loads and impacts. Updated Construction Rules and Regulations 2.01.07-85*", Moscow, 2016.

[2] Popov N.A. The recommendations on the updated dynamic calculation of buildings and structures on the action of the pulsation component of the wind load, Moscow, 2000

[3] T.A. Belash, "The peculiarities of the construction and operation of earthquake-proof buildings", Proceedings of Petersburg Transport University, № 4 (17), pp. 5-16, 2008.

[4] S.I. Merkulov, N.V. Polyakova, "Designing for possible progressive failure - ensuring structural safety in an emergency", Auditorium, 2016, № 4 (12), pp. 73-78

[5] H.W. Tieleman, R.E. Akins, Mean and fluctuating pressure distributions on rectangular prisms immersed in a variety of turbulent shear flows. AIAA/ASME/SIAM/APS , Ist National Fluid Dynamics Congress, july 25-28, 1998, vol. 2, pp. 1749-1756. Cincinnati, OHIO.

[6] T. Stathopoulos, M. Dumitrescu-Brulotte. Design recommendations for loading on buildings of intermediate height. ANNUAL Conference, 2527 May, 1988, vol. 1, pp. 275-293, Calgary. Canadian Society For Civil Engineering.

[7] Yu.P. Nazarov, Yu.N. Zhuk, V.N. Sibirkin, "Automated calculation of bearing structures of buildings," Industrial and Civil Engineering, 2006 No. 8, pp. 42-44.
[8] Kh.N. Mazhiev, D.K-S. Bataev, K.Kh. Mazhiev, A. Kh Mazhiev, "Materials and structures for construction and restoration of buildings and structures in seismic areas", Grozny, 2014, 652 p.

[9] J. Wacker, R. Friedrich, E.J. Plate, U. Bergdolt. Fluctuating wind load on cladding elements and roof pavers. J. of Wind Engineering and Industrial Aerodynamics, vol. 38, 1991, pp. 405-418.

[10] N.A. Popov, V.I. Travush, M.A. Berezin " Pedestrian Wind Comfort Study for Moscow International Business Center ", IV Symposium Environmental Effects on Buildings and People - Actions, influences, interactions, discomfort; Susiec, POLAND, 16-18, June 2004

[11] Vodopyanov, "The software package Lira version 9.6 for automated calculation and design of structures", in Industrial and Civil Engineering, 2009, № 4, pp. 59-60.

[12] H. Koss, J. Sahlmen, "Methods in pedestrian wind comfort assessment; theoretical and practical comparison", in "Impact of Wind and Storm on City life and Built Environment", Proceeding of the Workshop, June 3rd -4 th 2002 NANTES (France).

[13] J.A Wisse, H.W. Krus, F. Willemsen, "Wind comfort assessment by CFD", in "Impact of Wind and Storm on City life and Built Environment", Proceeding of the Workshop, June 3rd - 4th 2002 NANTES (France).

[14] D. K.S. Bataev, M. A. Gaziev, Adam Kh. Mazhiev, Aslan Kh. Mazhiev, "Investigation of the Properties of New Surface-Active Additives for Concretes", Materials Science Forum, Vol. 931, pp. 544-547, 2018.

[15] N.J. Cook, The designer's guide to wind loading of building structures. Part 2. Static structures, London, Butterwords, 1990.

[16] T. Stathopoulos, M. Dumitrescu-Brulotte, Design recommendations for loading on buildings of intermediate height, ANNUAL Conference, 2527 May, 1988, vol. 1, pp. 275-293, Calgary, Canadian Society For Civil Engineering.

[17] The wind tunnel 3-AT-17.5/3 of UNICON http://www.windtunnel.su/эродинамическая труба 3-AT-17,5/3 фирмы «УНИКОН»-http://www.windtunnel.su/ 